\title{
Application of Calixresorcinarenes as Chemical Sensors
}

\author{
Larbi Eddaif 1,2,*, Abdul Shaban ${ }^{2}$ and Judit Telegdi 1,2 \\ 1 Doctoral School on Materials Sciences and Technologies, Faculty of Light Industry and Environmental \\ Engineering, Óbuda University, Doberdó Str. 6, Budapest 1034, Hungary; Telegdi.judit@ttk.mta.hu \\ 2 Institute of Materials and Environmental Chemistry, RCNS, Hungarian Academy of Sciences, \\ 1117 Budapest, Magyar tudósok körútja 2; shaban.abdul@ttk.mta.hu; shaban.abdul@ttk.mta.hu \\ * Correspondence: eddaif.larbi1@gmail.com; Tel.: +36-20-276-5227
}

Received: 10 January 2019; Accepted: 26 March 2019; Published: 26 March 2019

\begin{abstract}
Calixresorcinarenes and calixarenes have seen extensive usage as receptors for cations, anions and even neutral molecules. Incorporation of binding capabilities and chemical groups that respond to analytes complexation has given these macrocycles additional advantages in applications as efficient selective chemical sensors. Three major types of macrocyclic calixresorcinarenes namely C-dec-9-en-1-ylcalix[4]resorcinarene (CAL 11U), C-trans-2, cis-6-octa1,5-dien-1-ylcalix[4]resorcinarene (CAL 9U) and C-nonylcalix[4]resorcinarene (CAL 10) were synthesized. They differ in the alkyl/alkenyl side chains. They were characterized by different techniques (melting point measurements, Fourier Transform Infra-Red spectroscopy FT-IR, Thermal Gravimetric analysis and Differential Scanning Calorimetry coupled with Mass Spectrometry TG-DSC-MS, Nuclear Magnetic Resonance spectroscopy NMR, and Powder X-Ray Diffraction measurements PXRD). Calixresorcinarene derivatives, immobilized onto Au surfaces of quartz crystal resonators, have been successfully applied to detect the presence of lead in aqueous solution.
\end{abstract}

Keywords: calixresorcinarenes; synthesis; XRD; FTIR; heavy metals detection

\section{Introduction}

Heavy metals are so harmful for both environment and human body, so their detection in environmental analysis is primordial, it can be measured using a number of analytical techniques such as anodic stripping voltammetry [1], inductively coupled plasma [2], and high performance liquid chromatography [3], these techniques are highly selective and sensitive, but they're very expensive and cannot be used for continuous in situ measurements. The use of chemical sensors has more advantages including the possibility to perform real-time continuous measurements and relatively inexpensive apparatus. The application of calixresorcinarene/ calixarene macrocycles as sensing platforms has known a huge usage, due to their binding affinities and complexation properties [4-6].

In this work, a series of calixresorcinarene macrocycles were synthesized, characterized by the mean of different techniques, and applied as chemical sensing platforms for the heavy metals ions detection. 


\section{Materials and Methods}

\subsection{Macrocycles Synthesis}

The synthesis was carried out based on the following recipe: $0.23 \mathrm{~mol}$ of aldehyde and $0.23 \mathrm{~mol}$ of resorcinol were dissolved into $240 \mathrm{~mL}$ absolute ethanol. The solution was cooled down to $0{ }^{\circ} \mathrm{C}$ in an ice bath, and then $37 \mathrm{~mL}$ of concentrated hydrochloric acid was injected, it was stirred for $1 \mathrm{~h}$, then heated and refluxed for another $12 \mathrm{~h}$. When the mixture was cooled down to room temperature, most of the product precipitated. An excess of water was added to completely precipitate the formed calixresorcinarene, which was filtered on a glass frit G3 type. The solid material was rinsed by distilled water and dried in vacuum over $\mathrm{NaOH}$ or $\mathrm{P}_{2} \mathrm{O}_{5}$. The recrystallization from methanol, and from a hexane: acetone $1: 1$ mixture gave yields of $49 \%, 50 \%$, and $48.8 \%$, respectively, for CAL $11 \mathrm{U}$, CAL 9U, and CAL 10, their molecular structures are shown in Figure 1 [7].

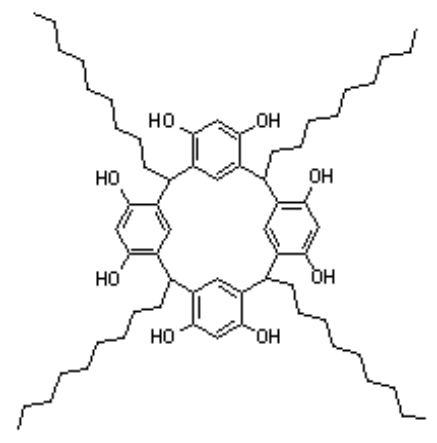

(a)

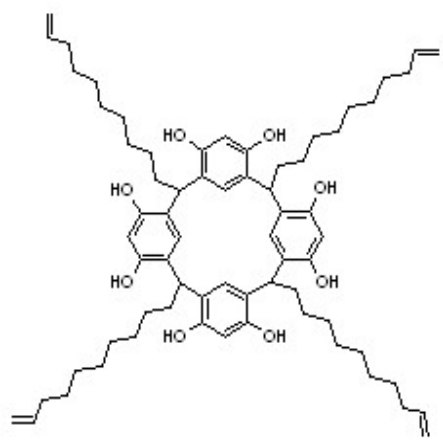

(b)

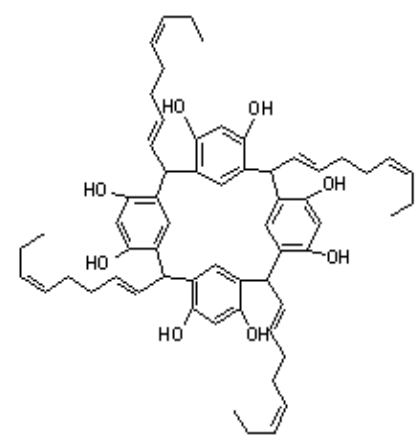

(c)

Figure 1. Molecular structures of the synthetized calix[4]resorcinarenes: (a) C-nonylcalix[4]resorcinarene; (b) C-dec-9-en-1-ylcalix[4]resorcinarene; and (c) C-trans-2, cis-6-octa-1,5-dien-1-ylcalix[4]resorcinarene [7].

\subsection{Macrocycles Characterization}

The synthesized calixaresorcinarene molecules were characterized by different techniques: Melting point measurements, Thermal Gravimetric analysis and Differential Scanning Calorimetry coupled with Mass Spectrometry (TG-DSC-MS), using a Setaram LabsysEvo thermal analyzer (Caluire-et-Cuire, France). Nuclear Magnetic Resonance (NMR) using a Varian VNMR SYSTEM ${ }^{\mathrm{TM}}$ spectrometer (Varian Inc., Palo Alto, CA, USA). Fourier Transform Infrared Spectroscopy (FTIR), using an FTIR Varian 2000 (Scimitar Series) FT-IR spectrometer (Varian Inc.) equipped with an MCT (mercury-cadmium-telluride) detector and with a single reflection diamond ATR unit (Specac Ltd., Orpington, UK). And Powder X-ray Diffraction (XRD), using a Philips Powder Diffractometer 1810/3710 with Bragg-Brentano parafocusing geometry (Amsterdam, The Netherlands). These techniques were used to determine the characteristic functional groups of the different synthesized molecules, their purity, their degree of crystallinity, furthermore to confirm their structures.

\subsection{Quartz Crystal Microbalance}

After the synthesis of the macrocycles and their characterization, it was time for their application as sensing platforms, our choice was to test one of the previous named molecules. The sensing method was the Quartz Crystal Microbalance with Impedance measurement (QCM-I), using a QCMI 008 unit (Microvacuum Ltd., Budapest, Hungary) controlled by a BioSense software, the measurements were carried out at room temperature, using a $5 \mathrm{MHz}$ AT-cut quartz crystal sensors with gold electrodes on both sides, and with a 14-mm diameter.

Firstly, a calixresorcinarene solution of $2 \mathrm{mg} / \mathrm{mL}$ was prepared by dissolving the convenient amount of the macrocycle in chloroform, then a volume of $10 \mu \mathrm{L}$ was drop coated on a clean quartz 
crystal, it was then dried under nitrogen flow at room temperature for $10 \mathrm{~min}$, besides it was used for the detection of a $200 \mathrm{ppm}$ lead nitrate solution.

\section{Results and Discussion}

\subsection{Macrocycles Characterization}

\subsubsection{Melting Points Measurements}

A way to determine the purity of a synthesized organic compound, is to determination its melting point (m.p.), since each specific molecule, has a determined m.p. range. Table 1 summarizes the m.p. of the prepared macrocycles, and confirming their purity.

Table 1. Experimental melting points of the synthesized molecules.

\begin{tabular}{ccc}
\hline Macrocycle Code & Macrocycle Name & Melting Points $\left({ }^{\circ} \mathrm{C}\right)$ \\
CAL 11U & C-dec-9-en-1-ylcalix[4]resorcinarene. & 277.0 \\
CAL 9U & C-trans-2, cis-6-octa-1,5-dien-1- & 314.0 (No thermal event was observed) \\
CAL 10 & ylcalix[4]resorcinarene. & 284.6 \\
\hline
\end{tabular}

\subsubsection{FTIR Measurements}

The FTIR spectra can help in the determination of the fucntional groups, furthermore, to confirme the chemical structures of the synthetized calix[4]resorcinarenes. The infrared spectra are shown in Figure 2, they were recorded in the wave number range $\left(4000-400 \mathrm{~cm}^{-1}\right)$.

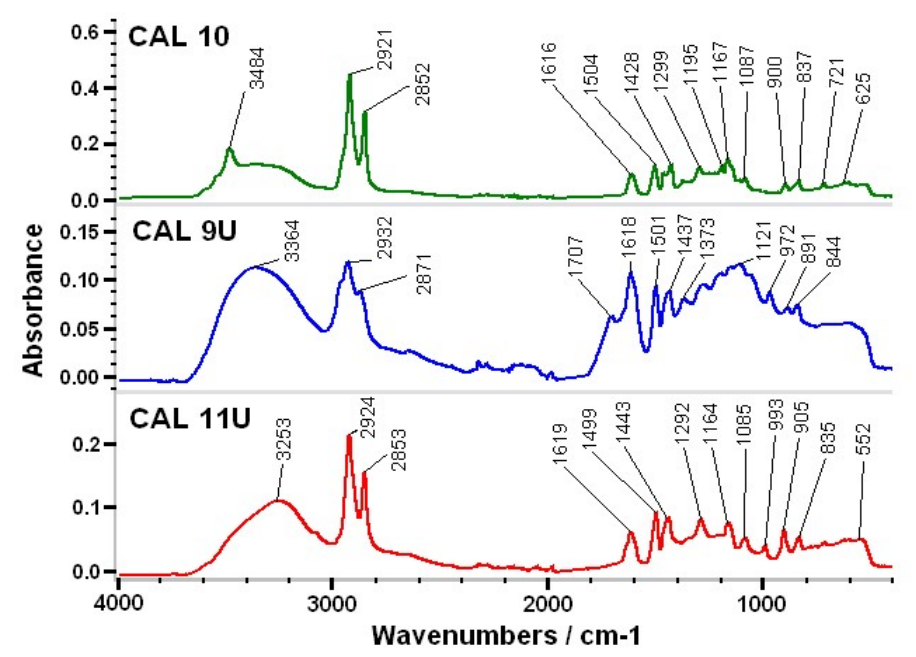

Figure 2. FTIR spectra of the macrocycles [7].

From Figure 2, a stretching frequency can be seen at 3364,3484, and $3253 \mathrm{~cm}^{-1}$ for CAL 9U, CAL 10 , and CAL 11U, respectively, which is due to the calixresorcinarene hydroxyl groups vibration. The difference between the three spectra can be observed in the fingerprint region (2000-400 $\left.\mathrm{cm}^{-1}\right)$, it can be explained by the diversity of the alkyl chains in the macrocycles, therefore all the functional groups describing the molecular structures were found on the spectra, which are shown in Tables 2-4 [7]. 
Table 2. IR parameters of CAL 11U [7].

\begin{tabular}{ccccc}
\hline Molecule Parts & Wave Number $\left(\mathbf{c m}^{-1}\right)$ & Bond & Nature of Vibration & Intensity \\
\hline \multirow{3}{*}{ Resorcinol } & 3253 & Associated O-H & Stretching & Strong and large \\
& 1164 & $\mathrm{C}-\mathrm{O}$ & Stretching & Medium \\
& 1292 & $\mathrm{O}-\mathrm{H}$ & In plan deformation & Medium \\
\hline \multirow{4}{*}{ Vinyl } & 3077 & $=\mathrm{C}-\mathrm{H}$ & Stretching & Medium \\
& 3034 & $=\mathrm{C}-\mathrm{H}$ & Stretching & Medium \\
& 1822 & $\mathrm{C}-\mathrm{H}$ & Deformation harmonics & Medium \\
& 1619 & $\mathrm{C}=\mathrm{C}$ & Stretching & Medium \\
\hline \multirow{5}{*}{ Aromatic } & 3074 & $=\mathrm{C}-\mathrm{H}$ & Stretching & Medium \\
& 1499 & $\mathrm{C}=\mathrm{C}$ & Stretching & Medium \\
& 1443 & $\mathrm{C}=\mathrm{C}$ & Stretching & Medium \\
& 1980 & $\mathrm{C}-\mathrm{H}$ & Deformation harmonics & Small \\
& 835 & $\mathrm{C}-\mathrm{H}$ & Out plan deformation & Medium to small \\
\hline \multirow{3}{*}{ Alkane } & 2924 & & Asymmetric stretching & Strong \\
& 2853 & $\mathrm{CH} 2$ & Symmetric stretching & Medium \\
& 721 & & Rocking & Medium to small \\
\hline
\end{tabular}

Table 3. IR parameters of CAL 9U [7].

\begin{tabular}{|c|c|c|c|c|}
\hline Molecule Parts & $\begin{array}{l}\text { Wave Number } \\
\left(\mathrm{cm}^{-1}\right)\end{array}$ & Bond & Nature of Vibration & Intensity \\
\hline \multirow{2}{*}{ Resorcinol } & 3364 & Associated O-H & Stretching & Strong and large \\
\hline & 1373 & $\mathrm{O}-\mathrm{H}$ & In plan deformation & Strong \\
\hline \multirow{5}{*}{ Aromatic } & 1598 & $\mathrm{C}=\mathrm{C}$ & Stretching & Small \\
\hline & 1560 & $\mathrm{C}=\mathrm{C}$ & Stretching & Small \\
\hline & 1437 & $\mathrm{C}=\mathrm{C}$ & Stretching & Medium \\
\hline & 1707 & $\mathrm{C}-\mathrm{H}$ & Deformation harmonics & Small \\
\hline & 891 & $=\mathrm{C}-\mathrm{H}$ & Out plan deformation & Medium \\
\hline \multirow{3}{*}{ Alkene } & 1652 & $\mathrm{C}=\mathrm{C}$ & Stretching & Medium \\
\hline & Trans & $=\mathrm{C}-\mathrm{H}$ & Out plan deformation & Medium \\
\hline & 1618 & $\mathrm{C}=\mathrm{C}$ & Stretching & Strong \\
\hline \multirow{4}{*}{ Alkane } & 2932 & $\mathrm{CH}_{2}$ & Asymmetric stretching & Strong \\
\hline & 2871 & $\mathrm{CH}_{3}$ & Symmetric stretching & Strong \\
\hline & 1437 & $\mathrm{CH}_{3}$ & In plan deformation & Medium \\
\hline & 729 & $\mathrm{CH}_{2}$ & Rocking & Medium \\
\hline
\end{tabular}

Table 4. IR parameters of CAL 10 [7].

\begin{tabular}{|c|c|c|c|c|}
\hline Molecule Parts & Wave Number $\left(\mathrm{cm}^{-1}\right)$ & Bond & Nature of Vibration & Intensity \\
\hline \multirow{3}{*}{ Resorcinol } & 3484 & Associated $\mathrm{O}-\mathrm{H}$ & Stretching & Strong \& large \\
\hline & 1195 & $\mathrm{C}-\mathrm{O}$ & Stretching & Medium to strong \\
\hline & 1377 & $\mathrm{O}-\mathrm{H}$ & In plan deformation & Medium \\
\hline \multirow{6}{*}{ Aromatic } & 3038 & $=\mathrm{C}-\mathrm{H}$ & Stretching & Very small \\
\hline & 1616 & $\mathrm{C}=\mathrm{C}$ & Stretching & Medium \\
\hline & 1504 & $\mathrm{C}=\mathrm{C}$ & Stretching & Medium \\
\hline & 1464 & $\mathrm{C}=\mathrm{C}$ & Stretching & Medium \\
\hline & 1979 & $\mathrm{C}-\mathrm{H}$ & Deformation harmonics & Small \\
\hline & 900 & $=\mathrm{C}-\mathrm{H}$ & Out plan deformation & Small \\
\hline \multirow{7}{*}{ Alkane } & 2852 & $\mathrm{CH}_{3}$ & Symmetric stretching & Strong \\
\hline & 1428 & $\mathrm{CH}_{3}$ & Asymmetric plan deformation & Medium \\
\hline & 2921 & $\mathrm{CH}_{2}$ & Asymmetric stretching & Strong \\
\hline & 1465 & $\mathrm{CH}_{2}$ & Scissoring & Medium \\
\hline & 721 & $\mathrm{CH}_{2}$ & Rocking & Medium \\
\hline & 1342 & $\mathrm{C}-\mathrm{H}$ & In plan deformation & Very small \\
\hline & 1167 & Linear chain $\mathrm{C}-\mathrm{C}$ & Stretching & Small \\
\hline
\end{tabular}




\subsubsection{NMR Analysis}

The ${ }^{1} \mathrm{H}$ and ${ }^{13} \mathrm{C}$ NMR spectra of the compounds CAL 10 and CAL 11U are shown in Figures 3-6 They present characteristic peaks for the aromatic and the aliphatic carbons and protons, confirming the suggested stuctures. The NMR spectra of the CAL $9 \mathrm{U}$ are not presented, because the compound is not soluble in the majority of deuterated solvents available. The development of a suitable solvent mixture, which could dissolve the macrocycle in a suitable concentration for the measurement is still in process.

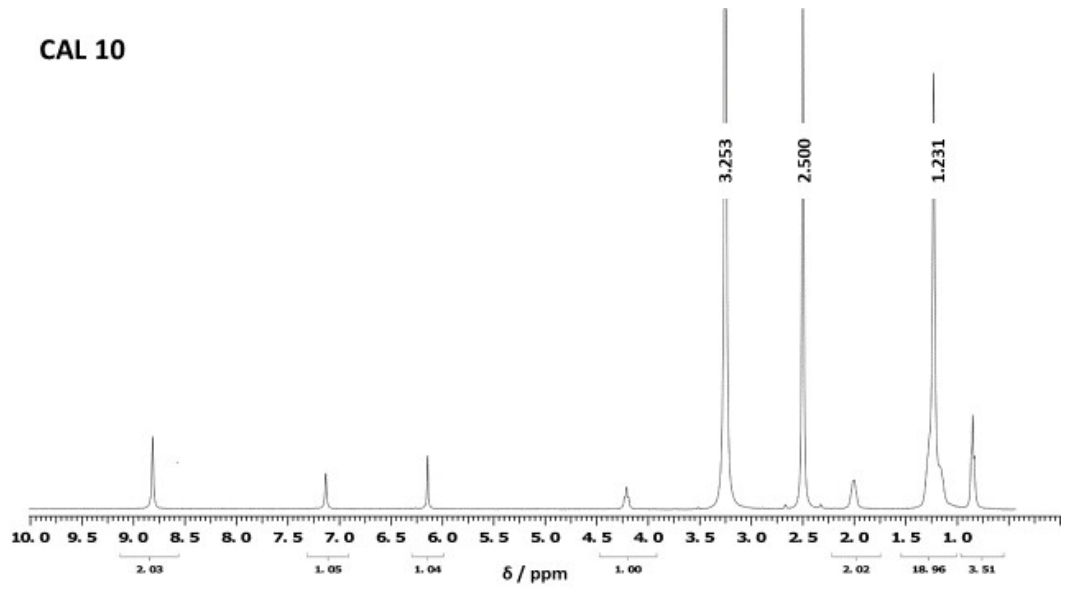

Figure 3. ${ }^{1} \mathrm{H}$ NMR spectra of CAL 10 [7].

CAL 10

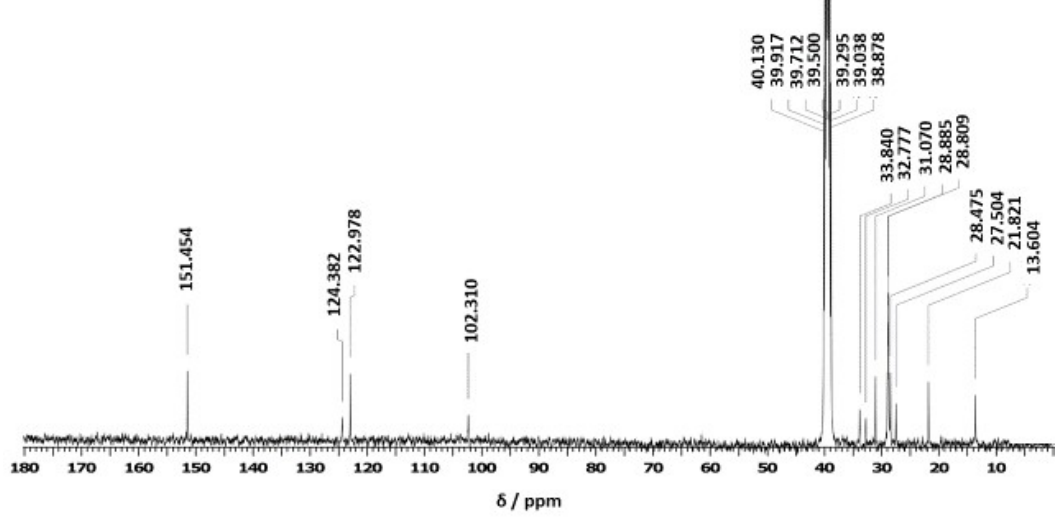

Figure $4 .{ }^{13} \mathrm{C}$ NMR spectra of CAL 10 [7].

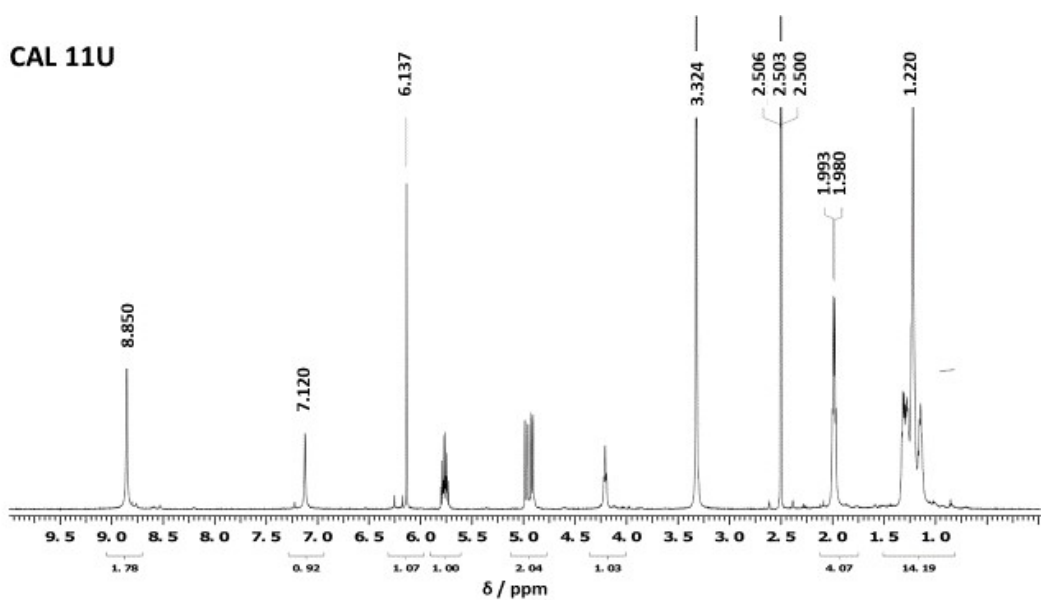

Figure 5. ${ }^{1} \mathrm{H}$ NMR spectra of CAL 11U [7]. 


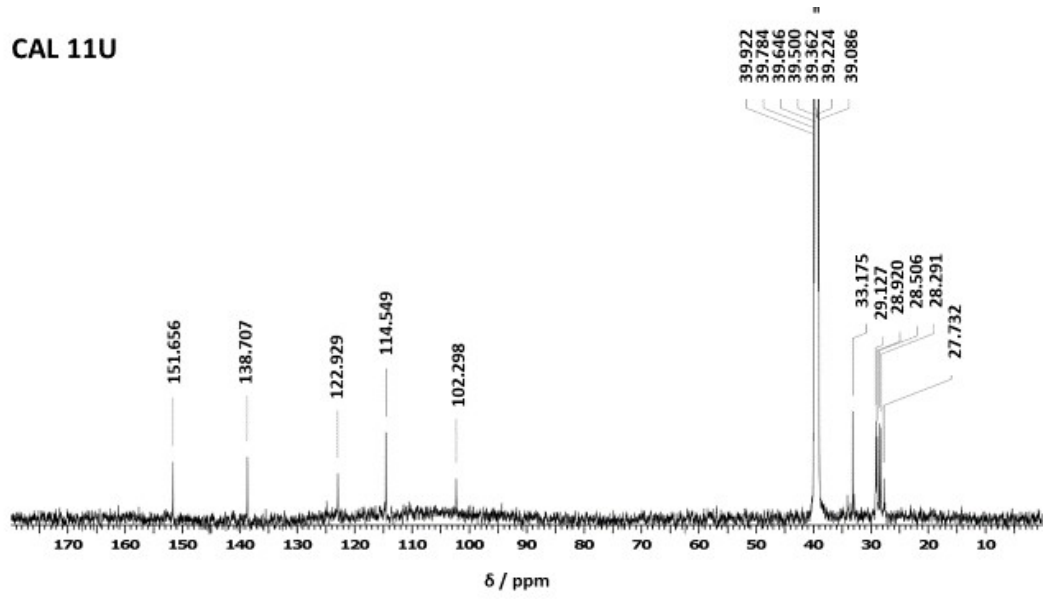

Figure $6 .{ }^{13} \mathrm{C}$ NMR spectra of CAL $11 \mathrm{U}$ [7].

- $\quad$ CAL 10

${ }^{1} \mathrm{H}$ NMR (DMSO-d6, $\left.400 \mathrm{MHz}, 40{ }^{\circ} \mathrm{C}\right) \delta(\mathrm{ppm}): 8.75(8 \mathrm{H}, \mathrm{s}) ; 7.12(4 \mathrm{H}, \mathrm{s}) ; 6.13(4 \mathrm{H}, \mathrm{s}) ; 4.23(4 \mathrm{H}, \mathrm{t}$, $\mathrm{J}=8.0 \mathrm{~Hz}) ; 2.02(8 \mathrm{H}, \mathrm{m}) ; 1.47-1.00(56 \mathrm{H}, \mathrm{m}) ; 0.82(12 \mathrm{H}, \mathrm{t}, \mathrm{J}=6.3 \mathrm{~Hz})$.

${ }^{13} \mathrm{C}$ NMR (DMSO-d6, $100 \mathrm{MHz}, 50{ }^{\circ} \mathrm{C}$ ) $\delta$ (ppm): 151.5; 124.4; 123.0; 102.3; 33.8; 32.8; 31.1; 28.9; $28.8 ; 28.5 ; 27.5 ; 21.8 ; 13.6$.

- CAL 11U

${ }^{1} \mathrm{H}$ NMR (DMSO-d6, $\left.600 \mathrm{MHz}, 25 \circ \mathrm{C}\right) \delta(\mathrm{ppm}): 8.85(8 \mathrm{H}, \mathrm{s}) ; 7.12(4 \mathrm{H}, \mathrm{s}) ; 6.13(4 \mathrm{H}, \mathrm{s}) ; 5.75(4 \mathrm{H}$, $\mathrm{m}) ; 4.98(4 \mathrm{H}, \mathrm{m}) ; 4.92(4 \mathrm{H}, \mathrm{m}) ; 4.22(4 \mathrm{H}, \mathrm{t}, \mathrm{J}=8.3 \mathrm{~Hz}) ; 2.07-1.97(16 \mathrm{H}, \mathrm{m}) ; 1.43-1.05(48 \mathrm{H}, \mathrm{m})$.

${ }^{13} \mathrm{C}$ NMR (DMSO-d6, $150 \mathrm{MHz}, 25^{\circ} \mathrm{C}$ ) $\delta$ (ppm): 151.7; 138.7; 124.7; 122.9; 114.5; 102.3; 33.2; 33.0; $29.2 ; 29.1 ; 28.9 ; 28.5 ; 28.3 ; 27.7$.

\subsubsection{TG-DSC-MS Investigations}

The aim of this part was, to determine the thermal stability of the prepared molecules, to measure their melting points moreover to determine any volatile content released from the samples at lower temperature (determination of any volatile contaminant). In Figure $7 \mathrm{a}$, the TG curves are plotted against temperature, while on Figure $7 \mathrm{~b}$, the corresponding heat flow curves are presented. The insert in Figure 7a shows a magnified part of the TG curves from the beginning of the measurement up to $145^{\circ} \mathrm{C}$, on which the mass losses at lower temperatures are clearly visible. It can be seen, that at lower temperatures (from 40 up to $120^{\circ} \mathrm{C}$ ) a small mass loss step (CAL 11U: $1.36 \%$, CAL 9U: $0.6 \%$ and CAL 10: $1.1 \%$ ) is present on the TG curve of all three investigated samples.

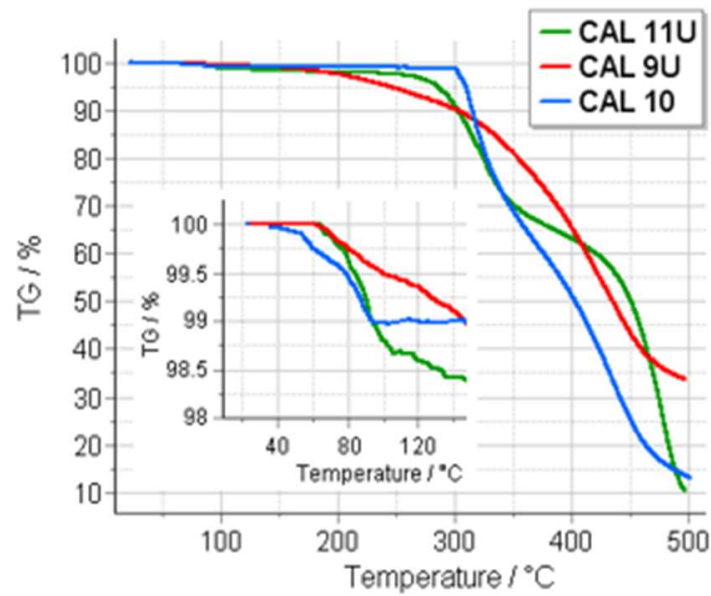

(a)

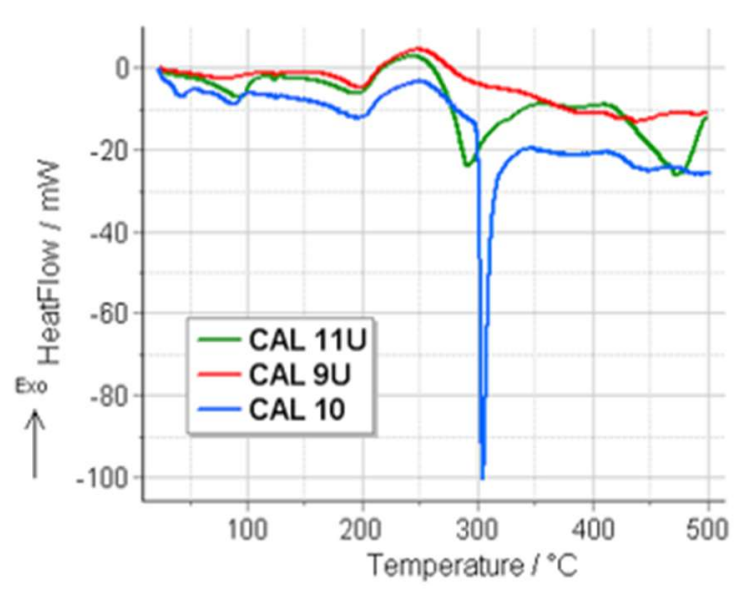

(b) 
Figure 7. The results of thermogravimetric (a), and differential scanning calorimetric (b) measurements (the inset in (a) is a magnification of the TG curve from the beginning of the measurement up to $150^{\circ} \mathrm{C}$ ) [7].

It can also be noticed, that the samples are having different thermal stabilities, the less stable is the CAL 9U, which can be explained by its higher degree of unsaturation, each hydrocarbon side chain contains two carbon-carbon double bonds. The degradation of CAL $9 \mathrm{U}$ starts above $150{ }^{\circ} \mathrm{C}$ and accelerates above $175{ }^{\circ} \mathrm{C}$. In contrary, the CAL 10 is having the highest thermal stability, from $120^{\circ} \mathrm{C}$ no mass loss occurs up to $300{ }^{\circ} \mathrm{C}$, above this temperature the calixresorcinarene degrades fast. This outstanding thermal stability can be the consequence of the saturated hydrocarbon side-chains in the molecule. Following this idea, the thermal stability of the CAL 11U having one carbon-carbon double bond at the end of the carbon chain, should lie in between the two above mentioned macrocycles, which is also observable on the Figure $7 \mathrm{a}$, the material starts to degrade above $250{ }^{\circ} \mathrm{C}$. The total mass losses determined up to $500{ }^{\circ} \mathrm{C}$ are having the following values for each calixarene: CAL 11U$89,76 \%$, CAL $9 \mathrm{U}-66.34 \%$ and CAL $10-86.94 \%$.

In Figure $7 \mathrm{~b}$, the heat flow curves of each calixaresorcinarene are plotted against temperature. It can be seen, that on all three heat flow curves a small endotherm can be observed around $90{ }^{\circ} \mathrm{C}$, accompanied by small mass losses which are the result of evaporation of physically bound water, or traces of residual solvents remained from the preparation process. Around $200{ }^{\circ} \mathrm{C}$, a more intensive endothermic transformation is observable. These endotherms can be the result of some internal molecular transformations in the common calixaresorcinarene ring of the molecules, since not all of them are accompanied by mass loss, additionally the peak maximum values differ only by $2-3{ }^{\circ} \mathrm{C}$ (endotherm peak maxima: CAL $11 \mathrm{U}-194.1^{\circ} \mathrm{C}$, CAL $9 \mathrm{U}-196.5^{\circ} \mathrm{C}$ and CAL $10-196.9^{\circ} \mathrm{C}$ ). Comparing the heat flow curves of the samples between 250 and $350^{\circ} \mathrm{C}$, a very sharp endotherm can be seen in the case of CAL 10, which corresponds to the melting of the molecule (onset temp. $\left(T_{0}\right): 300.75{ }^{\circ} \mathrm{C}$, peak maximum $\left(T_{\mathrm{m}}\right): 304.23{ }^{\circ} \mathrm{C}$, melting enthalpy $\left.(\Delta H): 266.7 \mathrm{~J} / \mathrm{g}\right)$. For CAL $11 \mathrm{U}$, in the above mentioned temperature range, a much smaller and broader endotherm (onset temp. $\left(T_{0}\right): 269.5^{\circ} \mathrm{C}$, peak maximum $\left(T_{\mathrm{m}}\right): 289.9^{\circ} \mathrm{C}$ ) is noticeable, which is due to the melting of the sample, however considering the shape of the peak, the calixaresorcinarene could be partly crystallized. On the heat flow curve of the CAL 9U, no thermal event is noticeable, which could mean, that the sample is amorphous. The events on the heat flow curves above $350^{\circ} \mathrm{C}$ are the result of the thermal degradation of the samples.

In Figures 8-10 [7], the mass spectrometric evolved gas analysis results are presented. The chosen spectra for each investigated compound corresponds to the point, where the release of the volatiles takes place at the highest rate (determined using the DTG curve, and corrected with the transfer time from the TGA to the mass spectrometer).

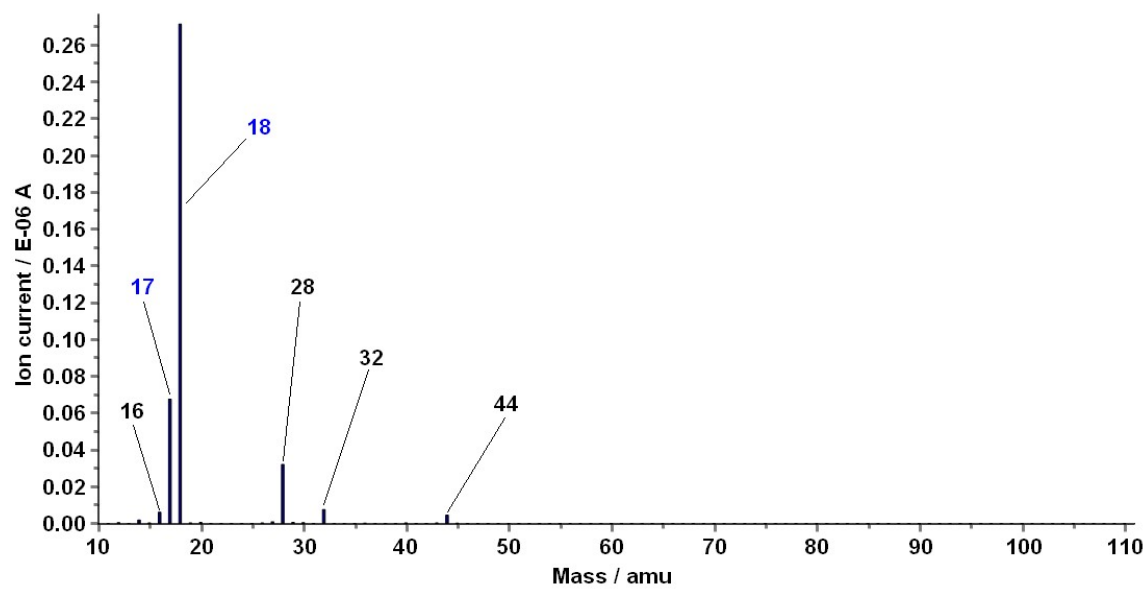

Figure 8. Mass spectra of the evolved volatiles form sample CAL 10 , at $87^{\circ} \mathrm{C}$ [7]. 


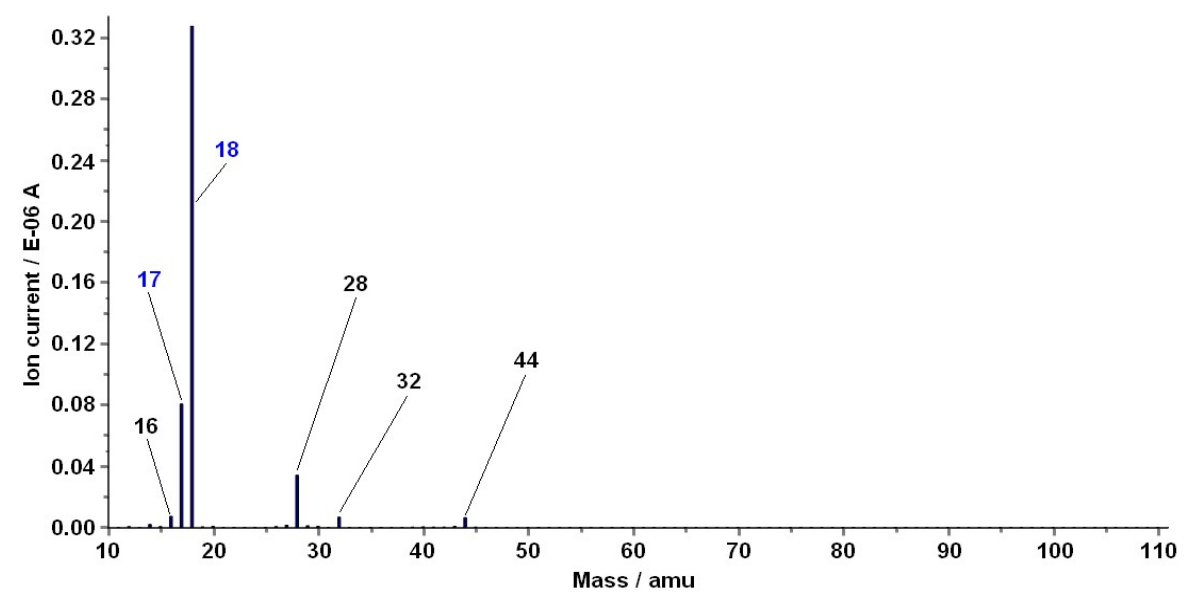

Figure 9. Mass spectra of the evolved volatiles form sample CAL 9U, at $83^{\circ} \mathrm{C}$ [7].

In Figures 8 and 9, the mass spectra of the evolved volatiles of CAL $10\left(\right.$ at $87^{\circ} \mathrm{C}$ ) and CAL 9U (at $\left.83^{\circ} \mathrm{C}\right)$ are shown. On both spectra, the main component is water $(\mathrm{m} / \mathrm{z}=18$ and $\mathrm{m} / \mathrm{z}=17)$, confirming the evaporation of physically bound water. The peaks with $\mathrm{m} / \mathrm{z}=44,32,28$, and 16 are the characteristic peaks of the components in air, which means, that some residual air was still present in the transfer line, which was entrapped during the sample changing process.

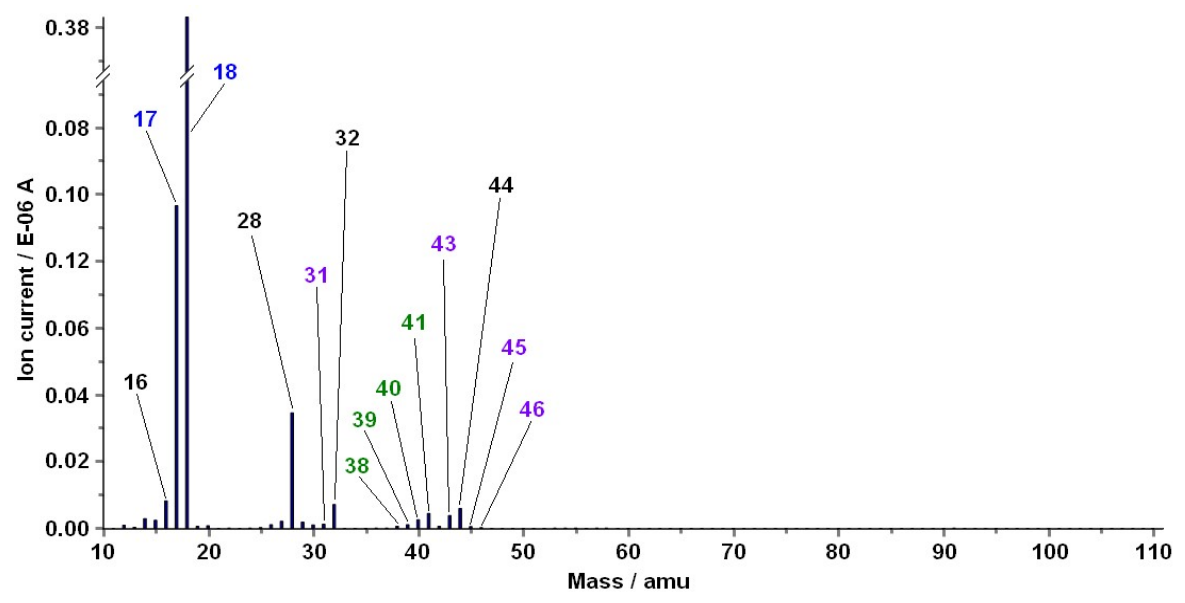

Figure 10. Mass spectra of the evolved volatiles form sample CAL 11U, at $92{ }^{\circ} \mathrm{C}$ [7].

In Figure 10, the analog mass spectra of the evolved volatiles released from sample CAL 11U (at $92{ }^{\circ} \mathrm{C}$ ) is plotted. While still the major component formed at $92{ }^{\circ} \mathrm{C}$ is water, some traces of acetonitrile $(\mathrm{m} / \mathrm{z}=41,40,39$, and 38) and ethanol $(\mathrm{m} / \mathrm{z}=46,45,43$, and 31) can be detected too. These are traces of impurities, which remained in the sample possibly from the preparation and purification processes. The characteristic peaks of the residual air are also visible.

\subsubsection{Powder X-ray Diffraction Studies}

The purpose of the XRD studies was to investigate the crystalline character of synthetized calixresorcinarenes. The diffractograms of compounds CAL 9U, CAL 10, and CAL 11U are presented in Figure 11. As it can be seen, the CAL 10 is totally crystalline, the CAL $11 \mathrm{U}$ is semi-crystalline, and the CAL $9 \mathrm{U}$ is practically amorphous. By the way, the obtained results are in perfect agreement with the data obtained from the thermal measurements. Based on the XRD patterns, CAL10 is crystallized, this fact can be observed in the heat flow curve of the sample as a very sharp melting endotherm around $300^{\circ} \mathrm{C}$. CAL $9 \mathrm{U}$ is practically amorphous because no thermal event was seen, and CAL 11U is partly crystallized, a small, wide melting endotherm on the heat flow curve confirms this observation. 


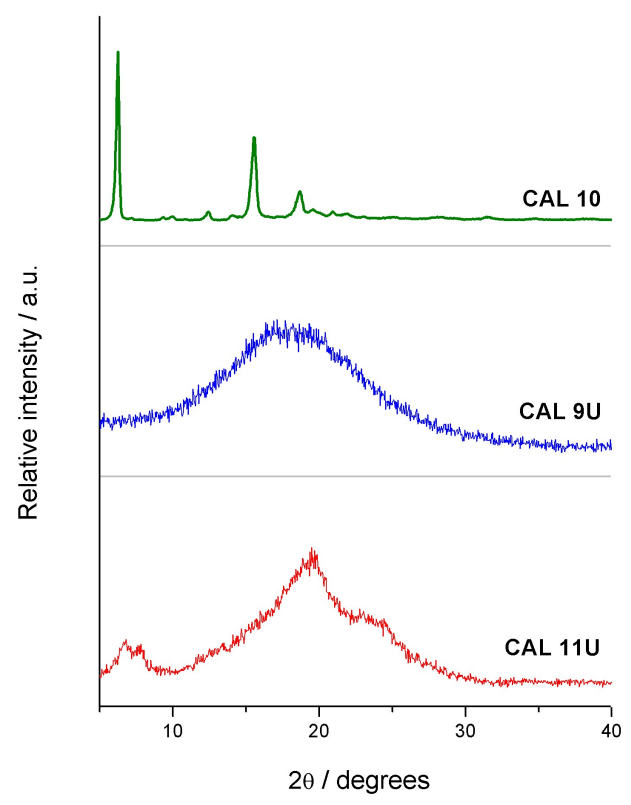

Figure 11. Powder X-ray diffractograms of the three calix[4]resorcinarenes [7].

\subsection{QCM-I Results}

The (QCM-I) is a system that possesses high frequency/ mass change sensitivity. It was used for the detection of lead nitrate solution of $200 \mathrm{ppm}$ concentration. The QCM quartz was exposed to heavy metals solution, leading to frequency variation and mass change (Figure 1).

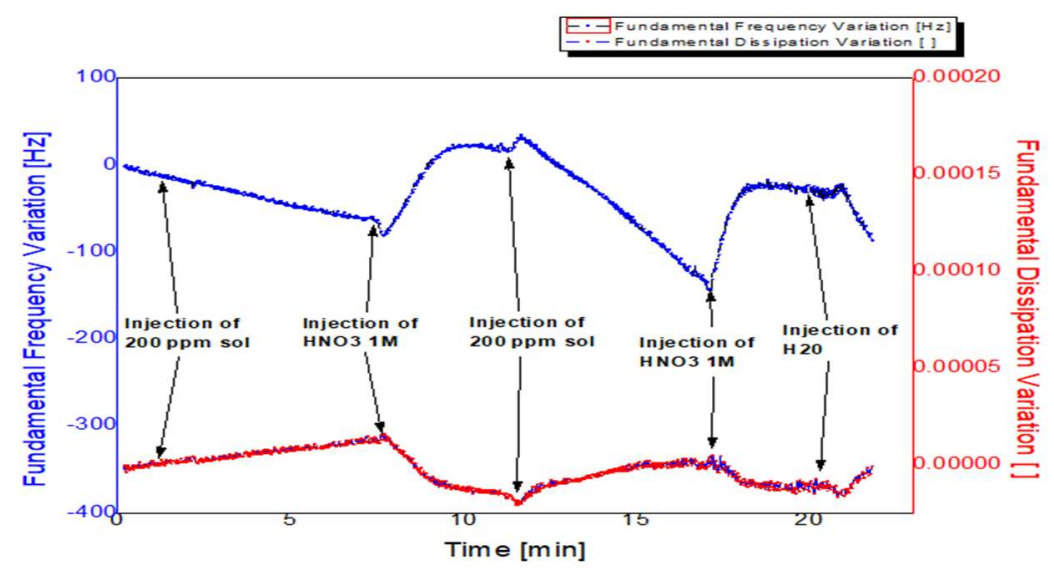

Figure 12. Variation of fundamental frequency, and fundamental dissipation energy due to the injection of heavy metals solution in time.

Figure 12 shows that after the injection, there's an adsorption of heavy metals ions on the surface by chemical complexation reaction between the heavy metals ions and the macrocycles attached to the surface, that's why the mass increases (the frequency decreases), but after washing the system with a $1 \mathrm{M} \mathrm{HNO}_{3}$ washing solution, the mass decreases (the frequency increases) which means a desorption of heavy metals ions from the surface and regeneration of the system, same procedure is repeated successfully which specifies the reusability, the reliability, and the reproducibility of the sensor.

The variation of dissipation (Figure 12: red curve) energy measures the viscoelastic properties of the adlayer. The lack of dissipation change indicates the non-deformation and the rigid characteristics of the layer on the surface. As we can see on Figure 12, there's a little change in 
dissipation energy due to the absorption of water molecules on the surface, then it becomes a little bit softer, but still the rigid character is dominating, so the application of Sauerbrey Equation (1) is valid, therefor it will give a correct mass estimation. The analysis was quantitative, the loaded mass of calixaresorcinarene was around $264.51 \mathrm{ng}$ and the film thickness was about $1.17 \mu \mathrm{m}$.

$$
\text { Sauerbrey equation: } \Delta m=-(C \Delta f / n)
$$

where $C=17.7 \mathrm{ng} \mathrm{Hz}^{-1} \mathrm{~cm}^{-2}$ for a $5 \mathrm{MHz}$ quartz crystal, $\Delta m=$ sauerbrey mass variation, $n=1,3,5$, and 7 is the overtone number, and $\Delta f=$ frequency variation.

\section{Conclusions}

A series of calixresorcinarene macrocycles were synthesized by a simple condensation reaction, they were characterized by different techniques (Melting points determination, NMR, FTIR, TG-DSCMS, and XRD).

The quartz crystal microbalance $(\mathrm{QCM})$ is a nanogram sensitive technique that utilizes acoustic waves generated by oscillating a piezoelectric single crystal quartz plate to measure mass. The results of the application of calixresorcinarene macrocycles as sensing platforms showed the usefulness of this technique for the detection of heavy metal ions (Lead nitrate solution) at very low level (ppm).

Funding: This research received no external funding.

Acknowledgments: The corresponding author would like to thank the Stipendium Hungaricum Scholarship Program for support.

Conflicts of Interest: The authors declare no conflict of interest.

\section{References}

1. McGaw, E.A.; Swain, G.M. A comparison of boron-doped diamond thin-film and Hg-coated glassy carbon electrodes for anodic stripping voltammetric determination of heavy metal ions in aqueous media. Anal. Chim. Acta 2006, 575, 180-189. doi:10.1016/j.aca.2006.05.094.

2. Valderi, L.D.; Dirce, P.; Adilson, J.C. Determination of heavy metals by inductively coupled plasma mass spectrometry after on-line separation and preconcentration. Spectrochimica. Acta Part B 1998, 53, 1527-1539. doi:10.1016/S0584-8547(98)00180-3.

3. Malik, A.K.; Kaur, V.; Verma, N. A review on solid phase microextraction-high performance liquid chromatography as a novel tool for the analysis of toxic metal ions. Talanta 2006, 68, 842-849. doi:10.1016/j.talanta.2005.06.005.

4. Gulino, A.; Lupo, F.; Cristaldi, D.A.; Pappalardo, S.; Capici, C.; Gattuso, G.; Notti, A.; Parisi, M.F. A viable route for lithium ion detection. Eur. J. Inorg. Chem. 2014, 2013, 442-449. doi:10.1002/ejic.201301213.

5. Cristaldi, D.A.; Fragala, I.; Pappalardo, A.; Toscano, R.M.; Ballistreri, F.P.; Tomaselli, G.A.; Gulino, A. Sensing of linear alkylammonium ions by a 5-pyrenoylamido-calix [5] arene solution and monolayer using luminescence measurements. J. Mater. Chem. 2012, 22, 675-683. doi:10.1039/C1JM13475B.

6. Ma, Y.-H.; Yuan, R.; Chai, Y.-Q.; Liu, X-L. A new aluminum (iii)-selective potentiometric sensor based on n, n'-propanediamide bis (2-salicylideneimine) as a neutral carrier. Mater. Sci. Eng. C 2010, 1, 209-213. doi:10.1016/j.msec.2009.10.005.

7. Eddaif, L.; Trif, L.; Telegdi, J.; Shaban, A. Calix[4]resorcinarene macrocycles: Synthesis, thermal behavior and crystalline characterization. J. Therm. Anal. Calorim. 2019. in press.

(C) 2019 by the authors. Licensee MDPI, Basel, Switzerland. This article is an open access article distributed under the terms and conditions of the Creative Commons Attribution (CC BY) license (http://creativecommons.org/licenses/by/4.0/). 